\title{
Avaliação de três anti-sépticos na redução da microbiota cutânea abdominal em gatos
}

\section{Evaluation of three antiseptic drugs on the reduction of cats abdominal cutaneus microbiota}

\author{
Carla Cristina Costa Nogueira, ${ }^{*}$ Robson Maia Franco, ${ }^{\star \star}$ Carmen Helena de Carvalho Vasconcellos, ${ }^{\star \star \star}$ \\ Teresinha Ferreira, ${ }^{\star \star \star \star}$ Amary Nascimento Jr. ${ }^{\star \star \star \star \star}$
}

\begin{abstract}
Resumo
O presente trabalho ressalta a importância da anti-sepsia no pré-operatório de pequenos animais para prevenção da ocorrência de infecções cirúrgicas e avalia a redução da microbiota cutânea abdominal em felinos (Felis catus) por três anti-sépticos de utilização rotineira (gluconato de clorexidina, iodo-povidona e timerosal) O gluconato de clorexidina e a iodo-povidona apresentaram resultados semelhantes e satisfatórios, com uma redução média de 99,51\% e 99,26\%, respectivamente, não havendo, estatisticamente, diferença significativa, indicando portanto, serem os agentes químicos mais adequados para a anti-sepsia do campo operatório abdominal em gatos. O timerosal, apesar de ter apresentado atividade de redução bacteriana, não obteve resultados tão satisfatórios, com uma média de $84,1 \%$, apresentando diferença significativa, a nível de $5 \%$, quando comparado com o gluconato de clorexidina e a iodo-povidona. Além disso, por ser um agente químico de uso proibido pelo Ministério da Saúde para a finalidade de anti-sepsia, torna-se inadequado para utilização no campo operatório abdominal em gatos.
\end{abstract}

Palavras-chave: gluconato de clorexidina; iodo-povidona; timerosal; bactéria; pele; gatos.

\section{Introdução}

A fonte mais comum de bactérias contaminantes da ferida cirúrgica é a microbiota residente na pele do animal. A preparação pré-operatória dos pacientes, incluindo a tricotomia e anti-sepsia do local cirúrgico, previnem contra exposição a esta microbiota reduzindo o risco de infecção pós-operatória. Desta forma, o uso criterioso de agentes antimicrobianos no pré-operatório e o manejo cuidadoso da ferida no pós-operatório são medidas de controle importantes. Um anti-séptico cirúrgico ideal deve ter as seguintes características: ser ativo contra uma grande variedade de bactérias, promovendo rapidamente a morte dos organismos, tanto de forma vegetativa quanto esporulada; estar disponível em soluções detergentes que removam a sujeira e a oleosidade da pele; não causar resposta inflamatória quando aplicado; manter a atividade em presença de material orgânico; ter efeito residual prolongado; ser de fácil aplicação e econômico (Phillips et al., 1991).

O presente trabalho avalia experimentalmente a atividade de três anti-sépticos (gluconato de clorexidina, iodo- povidona e timerosal) na redução da microbiota cutânea abdominal em gatos. Estes três agentes químicos estão disponíveis no mercado, sendo o gluconato de clorexidina um produto de uso recente na cirurgia veterinária brasileira, porém de uso rotineiro na Europa e Estados Unidos na preparação pré-operatória em pacientes humanos e veterinários. A iodo-povidona é o agente químico mais difundido e utilizado na cirurgia veterinária, assim como na humana. O timerosal, comercialmente conhecido como mertiolate, apesar de ter proibida a sua utilização como agente anti-séptico, continua a ser utilizado, não somente em procedimentos cirúrgicos veterinários, mas também humanos, talvez pelo seu baixo custo.

A idéia de avaliar estes anti-sépticos tem como finalidade apresentar aos profissionais da Medicina Veterinária um agente químico que seja realmente válido para o uso em pequenos animais; já que estes apresentam, em relação aos humanos, diferenças significativas como a cobertura de pêlos, anatomia e bactérias da pele, além dos hábitos de higiene.

\footnotetext{
*Médica Veterinária - Graduação em Medicina Veterinária pela UFF.

** Professor Adjunto IV do Depto. de Tecnologia dos Alimentos, UFF.

***Médica Veterinária - Mestre em Cirurgia Veterinária pela UFF.

${ }^{\star * \star \star}$ Professor Adjunto IV do Depto. de Patologia e Clínica Veterinária, UFF.

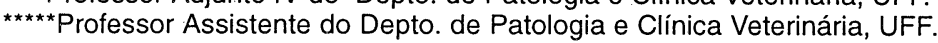




\section{Material e métodos}

\section{Animais}

Foram submetidos a este experimento 17 gatos (12 fêmeas e 5 machos), sem raça definida, aparentemente saudáveis e de pele íntegra. Quatro dos animais apresentavam menos de um ano de idade e os demais eram adultos. Apenas um animal vivia em apartamento, em contato com pisos de cerâmica e sinteco, sendo que os demais viviam em casa, mantendo contato com gramado, terra, pisos de cerâmica ou cimento.

\section{Anti-sépticos}

Os três anti-sépticos avaliados foram: gluconato de clorexidina $^{1}$ (GC), um agente biguanida, iodo-povidona ${ }^{2}$ (IP), um composto iodóforo, e o timerosal ${ }^{3}$ (TIM), um composto mercurial orgânico.

\section{Preparação do campo abdominal}

Os gatos foram submetidos a contenção farmacológica com cloridrato de cetamina ${ }^{4}(11 \mathrm{mg} / \mathrm{kg})$, associado ao sulfato de atropina $(0,05 \mathrm{mg} / \mathrm{kg})$, para que os procedimentos fossem realizados de maneira adequada.

Logo após a tranqüilização, os animais eram posicionados em decúbito dorsal, tricotomizados na região abdominal com máquina de tosa (lâmina \# 40). Os pêlos remanescentes livres foram retirados com o auxílio de um pincel. Tanto a lâmina da máquina, como o pincel eram desinfetados a cada procedimento com álcool a $70 \%$.

Após a tricotomia, três campos alinhados longitudinalmente eram demarcados com um lápis dermatográfico, delimitados por uma placa de alumínio quadricular $(4 \mathrm{~cm} \times 4 \mathrm{~cm})$ esterilizada a cada procedimento.

Na região delimitada no abdômen do animal, friccionavase um swab estéril, colocado em um tubo contendo $2 \mathrm{ml}$ de solução salina estéril, para análise quantitativa da microbiota superficial da pele.

Em seguida, procedeu-se à aplicação dos anti-sépticos com o auxílio de chumaços de gaze manuseados com pinças esterilizadas, dentro das áreas demarcadas, sempre na seguinte ordem: campo anterior - IP, central - GC e posterior - TIM. Após um tempo de cinco minutos, friccionava-se um swab para cada campo anteriormente mencionado, objetivando desta maneira avaliar a redução da microbiota pela atuação de cada anti-séptico.

Estes swabs eram colocados também em tubos identificados contendo $2 \mathrm{ml}$ de solução salina estéril. Assim, cada animal apresentava quatro amostras, sendo uma anterior a aplicação dos anti-sépticos e outras três referentes à area de atuação de cada um deles. As amostras eram imediatamente transportadas para o laboratório da disci- plina de Doenças Infecciosas dos Animais Domésticos da UFF, onde procediam-se as semeaduras em meio de cultivo apropriado.

Para facilitar a utilização, os anti-sépticos foram colocados em frascos menores esterilizados e toda semana eram avaliados, através de suas semeaduras em meios de cultivo, para certificar a esterilidade das soluções.

\section{Meio de cultivo e contagem de UFCs}

As amostras foram semeadas em agar-sangue, preparado acrescentando-se $7,5 \%$ de sangue de carneiro ao meio base (Agar Casoy ${ }^{5}$ ).

A semeadura das amostras foi realizada de maneira asséptica, em placas de Petri, por meio da técnica de espalhamento direto dos quatro swabs, um em cada placa, previamente identificada da seguinte maneira: Gato 1 antes, Gato 1 - GC, Gato 1 - IP, Gato 1 - TIM, e assim por diante, até Gato 17. As placas eram em seguida incubadas em estufa a uma temperatura de $37^{\circ} \mathrm{C}$ e, após um período de 48 horas, procedia-se à contagem de unidades formadoras de colônias (UFCs) crescidas, com halo de hemólise ou não.

\section{Análise estatística}

Os percentuais de redução bacteriana total (UFCs com halo de hemólise ou não) e das UFCs com halo de hemólise, foram calculados para cada procedimento a partir da contagem do número de UFCs, através da seguinte fórmula: [(UFCs antes - UFCs após) / UFCs antes] x 100.

A análise de variância, através do teste $F$ de Snedecor, foi utilizada no cálculo estatístico para determinar a significância das percentagens de redução bacteriana total (UFCs com halo de hemólise ou não) e de UFCs com halo de hemólise. O mesmo procedimento foi utilizado para avaliar a significância dos percentuais de redução bacteriana total entre os anti-sépticos.

\section{Resultados}

Os resultados percentuais de redução bacteriana total (UFCs com halo de hemólise ou não) e das UFCs com halo de hemólise são apresentados nas tabelas 1 e 2 .

Com relação às características morfotintoriais das bactérias cutâneas dos gatos submetidos ao experimento, através da coloração de Gram, observou-se com freqüência cocos Gram-positivos e bastonetes Gram-positivos e Gramnegativos. Foi observado ainda o crescimento de fungos em algumas amostras.

Das 17 amostras cultivadas, 15 apresentaram UFCs com halo de hemólise. A contagem total de UFCs para cada animal encontra-se no Quadro 1. 
Tabela 1: Percentuais de redução bacteriana total, após a utilização de cada anti-séptico.

\begin{tabular}{|c|c|c|c|}
\hline \multicolumn{4}{|c|}{ ANTI-SÉPTICOS } \\
\hline AlmWus & C6. (1.) & $\mathrm{PP}(\%)$ & 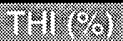 \\
\hline GATO 01 & 100 & 100 & 16,67 \\
\hline GATO 02 & 100 & 100 & 50 \\
\hline GATO 03 & 100 & 100 & 65 \\
\hline GATO 04 & 100 & 99,75 & 97,53 \\
\hline GATO 05 & 100 & 100 & 88,88 \\
\hline GATO 06 & 100 & 100 & 80 \\
\hline GATO 07 & 100 & 100 & 99,59 \\
\hline GATO 08 & 100 & 100 & 99,20 \\
\hline GATO 09 & 100 & 99,50 & 98 \\
\hline GATO 10 & 100 & 100 & 98,03 \\
\hline GATO 11 & 100 & 100 & 100 \\
\hline GATO 12 & 100 & 100 & 100 \\
\hline GATO 13 & 93,75 & 90,62 & 90,62 \\
\hline GATO 14 & 98,30 & 98,30 & 59,32 \\
\hline GATO 15 & 99,62 & 100 & 98,87 \\
\hline GATO 16 & 100 & 99,80 & 97,20 \\
\hline GATO 17 & 100 & 99,41 & 97,67 \\
\hline
\end{tabular}

Tabela 2: Percentuais de redução de UFCs com halo de hemólise após utilização de cada anti-séptico.

\begin{tabular}{|c|c|c|c|}
\hline \multicolumn{4}{|c|}{ ANTI-SÉPTICOS } \\
\hline WWlbling & 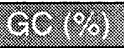 & 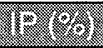 & (in) \\
\hline GATO 01 & 100 & 100 & 66,70 \\
\hline GATO 02 & 100 & 100 & 50 \\
\hline GATO 03 & 100 & 100 & 12,50 \\
\hline GATO 04 & 100 & 100 & 80 \\
\hline GATO 05 & $\ldots$ & $\ldots$ & $\ldots$ \\
\hline GATO 06 & $\ldots$ & $\ldots$ & $\ldots$ \\
\hline GATO 07 & 100 & 100 & 100 \\
\hline GATO 08 & 100 & 100 & 99,60 \\
\hline GATO 09 & 100 & 100 & - \\
\hline GATO 10 & 100 & 100 & 100 \\
\hline GATO 11 & 100 & 100 & 100 \\
\hline GATO 12 & 100 & 100 & 100 \\
\hline GATO 13 & 100 & 100 & 91,67 \\
\hline GATO 14 & 100 & 100 & 35,71 \\
\hline GATO 15 & 100 & 100 & 92,59 \\
\hline GATO 16 & 100 & 100 & 99,60 \\
\hline GATO 17 & 100 & 100 & 100 \\
\hline
\end{tabular}

Quadro 1: Contagem total de unidades formadoras de colônias (UFCs)

\begin{tabular}{|c|c|c|c|c|c|c|c|c|c|c|c|c|c|}
\hline \multirow[t]{3}{*}{ ANIMAL } & \multirow{3}{*}{\begin{tabular}{|c|} 
AMBIENTE \\
Local/Contato \\
\end{tabular}} & \multirow{2}{*}{\multicolumn{3}{|c|}{ ANTES }} & \multicolumn{6}{|c|}{ RESULTADOS (UFCs) } & & & \\
\hline & & & & & \multicolumn{3}{|c|}{$G C$} & \multicolumn{3}{|c|}{ IP } & \multicolumn{3}{|c|}{ THI } \\
\hline & & n.h. & h. & Tot. & n.h. & h. & Tot. & n.h. & h. & Tot. & n.h. & h. & Tot \\
\hline GATO 01 & CASA Ci, T & 9 & 3 & 12 & 0 & 0 & 0 & 0 & 0 & 0 & 9 & 1 & 10 \\
\hline GATO 02 & CASA Ci, T & 10 & 2 & 12 & 0 & 0 & 0 & 0 & 0 & 0 & 5 & 1 & 6 \\
\hline GATO 03 & CASA Ce, $\mathrm{Ci}, \mathrm{G}, \mathrm{T}$ & 30 & 8 & 38 & 0 & 0 & 0 & 0 & 0 & 0 & 6 & 7 & 13 \\
\hline GATO 04 & $\mathrm{CASA} \mathrm{Ce}, \mathrm{Ci}, \mathrm{G}, \mathrm{T}$ & 400 & 5 & 405 & 0 & 0 & 0 & 1 & 0 & 1 & 9 & 1 & 10 \\
\hline GATO 05 & APTO/Ce,Si & 9 & 0 & 9 & 0 & 0 & 0 & 0 & 0 & 0 & 1 & 0 & 1 \\
\hline GATO 06 & CASA Ci & 5 & 0 & 5 & 0 & 0 & 0 & 0 & 0 & 0 & 1 & 0 & 1 \\
\hline GATO 07 & CASA Ci & 12 & 15 & 27 & 0 & 0 & 0 & 0 & 0 & 0 & 2 & 0 & 2 \\
\hline GATO 08 & CASA Ci,G,T & 250 & 250 & 500 & 0 & 0 & 0 & 0 & 0 & 0 & 3 & 1 & 4 \\
\hline GATO 09 & CASA Ci & 200 & 1 & 201 & 0 & 0 & 0 & 1 & 0 & 1 & 3 & 1 & 4 \\
\hline GATO 10 & CASACi & 50 & 1 & 51 & 0 & 0 & 0 & 0 & 0 & 0 & 1 & 0 & 1 \\
\hline GATO 11 & CASA Ci & 100 & 1 & 101 & 0 & 0 & 0 & 0 & 0 & 0 & 0 & 0 & 0 \\
\hline GATO 12 & CASACi & 80 & 2 & 82 & 0 & 0 & 0 & 0 & 0 & 0 & 0 & 0 & 0 \\
\hline GATO 13 & CASA Ci,T & 20 & 12 & 32 & 2 & 0 & 2 & 3 & 0 & 3 & 2 & 1 & 3 \\
\hline GATO 14 & CASA Ci,T & 45 & 14 & 59 & 1 & 0 & 1 & 1 & 0 & 1 & 15 & 9 & 24 \\
\hline GATO 15 & CASA Ci,T & 240 & 47 & 267 & 1 & 0 & 1 & 0 & 0 & 0 & 1 & 2 & 3 \\
\hline GATO 16 & $\mathrm{CASA} \mathrm{Ce}, \mathrm{Ci}, \mathrm{G}, \mathrm{T}$ & 250 & 250 & 500 & 0 & 0 & 0 & 1 & 0 & 1 & 13 & 1 & 14 \\
\hline GATO 17 & $\mathrm{CASA} \mathrm{Ce}, \mathrm{Ci}, \mathrm{G}, \mathrm{T}$ & 160 & 12 & 172 & 0 & 0 & 0 & 1 & 0 & 1 & 4 & 0 & 4 \\
\hline
\end{tabular}

$\mathrm{Ce}=$ cerâmica; $\mathrm{Ci}=$ cimento; $\mathrm{G}=$ grama; $\mathrm{Si}=$ sinteco; $\mathrm{T}=$ terra; $\mathrm{GC}=$ gluconato de clorexidina; $\mathrm{IP}=$ iodo povidona; $\mathrm{THI}=$ thimerosal; $\mathrm{n} . \mathrm{h} .=$ não hemolítica; $\mathrm{h}=$ hemolítica; Tot. = total.

Ressalta-se ainda que não foi observada dermatite de contato aguda após a aplicação dos anti-sépticos.

A análise estatística permitiu observar que houve uma redução bacteriana significativa, a nível de $1 \%$, pela atuação dos três anti-sépticos, não só na avaliação do percentual de redução bacteriana total como nas de UFCs com halo de hemólise. A média dos percentuais de redução bacteriana de cada anti-séptico foi calculada e representada graficamente, encontrando-se os seguintes valores: (1) Média percentual de redução bacteriana total - 99,51\% (GC); 99,26\% (IP) e $84,1 \%$ (TIM) (Fig.1) e (2) Média percentual de redução de UFCs com halo de hemólise - 100\% (GC); 100\% (IP) e 75,22\% (TIM) (Fig.2). 


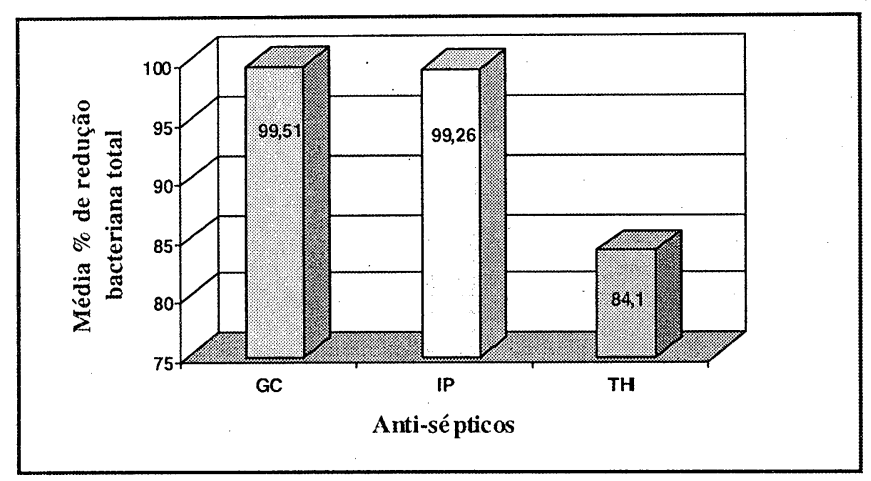

Figura 1: Média dos percentuais de redução bacteriana total da microbiota cutânea abdominal de gatos após utilização de 3 antisépticos.

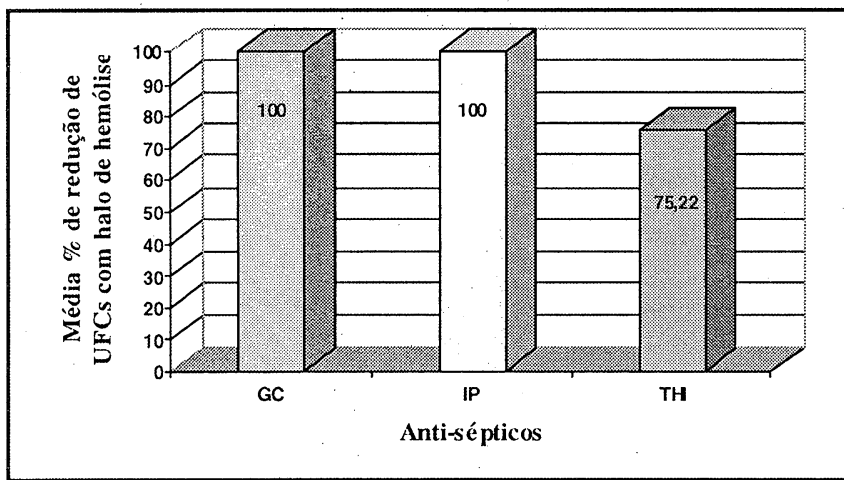

Figura 2 - Média dos percentuais de redução de UFCs com halo de hemólise da microbiota cutânea abdominal de gatos após utilização de 3 anti-sépticos.

Comparativamente, não houve diferença significativa entre o GC e a IP, porém houve diferença significativa, ao nível de $5 \%$, entre estes e o TIM.

\section{Discussão}

A utilização de agentes anti-sépticos adequados para a preparação do campo operatório objetivando a prevenção de infecções pós-operatórias em pequenos animais é de capital importância, uma vez que a maioria das técnicas pré-operatórias de anti-sepsia, principalmente em relação ao uso de agentes químicos, são baseadas em estudos humanos. Como há diferenças significativas entre estas espécies, não seria válido extrapolar os resultados encontrados na literatura da medicina humana. Romatowski (1989), em uma revisão de literatura sobre a prevenção e controle de infecções cirúrgicas comenta que a natureza limitada de informações veterinárias leva à necessidade frequente da recorrência à literatura médica humana. Entretanto, há riscos inerentes em extrapolar informações de uma espécie para outra. Até que trabalhos veterinários suficientes sejam desenvolvidos, as técnicas de controle de infecção aplicadas em hospitais humanos poderiam servir de guia para a cirurgia em pequenos animais.
A elevada ocorrência de UFCs com halo de hemólise ressalta a importância da anti-sepsia do campo operatório abdominal frente ao potencial patogênico das espécies bacterianas que apresentam este comportamento.

Nenhum animal submetido a este experimento apresentou dermatite de contato aguda após a aplicação dos antisépticos, porém, dois trabalhos realizados por Osuna et al., (1990, 1992), relataram a ocorrência de reações dérmicas agudas em aproximadamente $50 \%$ das áreas preparadas com iodo-povidona. Por causa deste problema, este produto tem sido amplamente substituído pelo clorexidine para preparação do campo operatório em hospitais humanos. Após revisar a literatura, o mesmo autor concluiu que a significativa dermatite de contato aguda após a preparação pré-operatória da pele é provavelmente subestimada e ainda, que a alta incidência de reações dérmicas observadas após a aplicação de iodo-povidona faz com que o clorexidine seja mais indicado para alguns pacientes.

O gluconato de clorexidina e a iodo-povidona são, comprovadamente, agentes bactericidas de amplo espectro. No entanto, vários autores relatam em seus trabalhos vantagens do $\mathrm{GC}$ em relação à IP, tais como a atividade residual prolongada, manutenção da atividade antibacteriana em presença de matéria orgânica e baixa reação tecidual (Lee et al., 1988; Boddie et al., 1990; Osuna et al.,1990; Phillips et al., 1991; Swaim et al.,1991; Fries, 1993).

Neste experimento observou-se estatisticamente que o GC e a IP apresentaram atividade similar de redução bacteriana, sendo, portanto, compatível com os resultados dos trabaIhos de Osuna et al. (1990), Phillips et al. (1991) e Swaim et al. (1991). O timerosal, apesar de ter apresentado atividade de redução bacteriana, não obteve resultados tão satisfatórios quanto os demais.

Inúmeros pesquisadores demonstraram que a ação antibacteriana dos compostos mercuriais na célula vegetativa é primariamente bacteriostática e apenas levemente bactericida, sendo imprudente a sua utilização quando se dispõe de outros agentes mais eficientes. Os detritos de matéria orgânica prontamente dissipam sua ação (Huber, 1992).

A portaria $n^{2} 930$, de 27 de agosto de 1992, anexo V, do Ministério da Saúde, proíbe que os compostos mercuriais orgânicos sejam utilizados para a finalidade de anti-sepsia. O timerosal, um composto mercurial orgânico, apesar de não ser recomendado, continua a ser um dos mais utilizados nos hospitais brasileiros (Martins et al., 1991).

\section{Conclusões}

Nas condições do presente experimento pode-se concluir, em relação à atividade de redução bacteriana, que o gluconato de clorexidina e a iodo-povidona apresentaram resultados semelhantes e satisfatórios, indicando, portanto, serem os agentes químicos mais adequados para a 
anti-sepsia do campo operatório abdominal em gatos. O timerosal não apresentou resultados tão satisfatórios na atividade de redução bacteriana quando comparado com o gluconato de clorexidina e a iodo-povidona, concluindo-se desta maneira que, além de ser um composto de uso proibido pela Lei Federal para a finalidade de anti-sepsia, não seria o agente químico mais adequado para preparação pré-operatória do campo abdominal em gatos.

\section{Abstract}

This study evaluate the reduction of the cutaneous microbiota on the abdominal region of the feline (Felis catus)by three antiseptic drugs (chlorhexidine gluconate, povidone-iodine and thimerosal). Chlorhexidine gluconate and povidone-iodine yields similar results with mean reduction of $99.51 \%$ and $99.26 \%$ respectively, and did not have significant statistical differences, suggesting to be the most appropriated chemical agents for cats abdominal opperative site antisepsis. Thimerosal, although showing bacterial reduction, did not offered satisfactory results, with a mean reduction of $84.1 \%$, and when compared statistically with chlorhexidine gluconate and povidone-iodine, showed significant difference at $5 \%$ level of confidence. Besides, being a forbidden chemical agent by the federal law for antisepsis, thimerosal becomes improper for cats abdominal opperative site.

Keywords: chlorhexidine gluconate; povidone-iodine; thimerosal; bacterium; skin; cats.

\section{Agradecimentos}

Os autores expressam seus agradecimentos a Heldo Sebastião Nogueira, Estatístico Analista, pelo desenvolvimento dos cálculos estatísticos, e também à Ceras Johnson S.A. e Merck S.A. Indústrias Químicas, pelo fornecimento dos produtos utilizados neste trabalho.

\section{Referências bibliográficas}

BODDIE, R. L., WATTS, J. L., NICKERSON, S. C. In vitro and in vivo evaluation of a $0,5 \%$ chlorhexidine gluconate teat dip. J. Am. Vet. Med. Assoc., v.196, p. 890-893, 1990.

BRASIL. Ministério da Saúde. Gabinete do Ministro. Portaria n. 930 de 27 de agosto de 1992. Diário Oficial. Brasília, DF, 4 set. de 1992, p. 12279 -12282. Seção I.

FRIES, C. L. Assessment and Preparation of the Surgical Patient. In: SLATTER, D. Textbook of Small Animal Surgery. 2 ed. Philadelphia: W.B. Saunders. 1993. 2 v. 2370 p. v. I, Section 2, Chapter 13, p.137-147.

HUBER, W. G. Antissépticos e desinfetantes. In: BOOTH, N. H.; McDONALD, L. E. Farmacologia e Terapêutica em Veterinária. 6. ed. Rio de Janeiro: Guanabara Koogan. 1992. 997p. Seção 14, cap. 47, p. 671-632.

LEE, A. H., SWAIM, S. F., McGUIRE, J. A., HUGHES, K. S. Effects of chlorhexidine diacetate, povidone-iodine and polyhidroxidine on wound healing in dogs. J. Am. Anim. Hosp. Assoc., v. 24, p. 77-84, 1988.

MARTINS, F. M., SILVA, M. G., GONTIJO, P. P. Relação entre a resistência a antimicrobianos e anti-sépticos em
Pseudomonas aeruginosa. Rev. Microbiol., v. 22, p. 3438, 1991.

OSUNA, D. J., DeYOUNG, D. J., WALKER, R. L. Comparison of three skin preparation techniques in the dog. Part 1: Experimental trial. Part 2: Clinical trial in 100 dogs. Vet. Surg., v. 19, p. 14-23, 1990.

OSUNA, D. J., DeYOUNG, D. J., WALKER, R. L. Comparison of an antimicrobial adhesive drape and povidone-iodine preoperative skin preparation in dogs. Vet. Surg., v. 21, p. 458-462, 1992.

PHILLIPS, M. F., VASSEUR, P. B., GREGORY, C. R. Chlorhexidine diacetate versus povidone-iodine for preoperative preparation of the skin: a prospective randomized comparison in dogs and cats. J. Am. Anim. Hosp. Assoc., v. 27, p. 105-108, 1991.

ROMATOWSKI, J. Prevention and control of surgical wound infection. J. Am. Vet. Med. Assoc., v.194, p. 107-113, 1989.

SWAIM, S. F., RIDDELL, K. P., GEIGER, D. L., HATHCOCK, T. L., McGUIRE, J. A. Evaluation of surgical scrub and antiseptic solutions for surgical preparation of canine paws. J. Am. Vet. Med. Assoc., v. 198, p. 1941-1945, 1991. 